\title{
Verbenaceae no Parque Estadual do Pico do Itambé, Estado de Minas Gerais, Brasil
}

Pedro Henrique Cardoso ${ }^{1,2,5}$, (1) Luiz Menini Neto $^{1}$, Pedro Henrique Nobre ${ }^{3}$,

(1) Marcelo Trovó ${ }^{2,4}$ e (1) Fátima Regina Gonçalves Salimena ${ }^{1}$

Recebido: 05.02.2020; aceito: 06.05.2020

Como citar: Cardoso, P.H., Menini Neto, L., Nobre, P.H., Trovó, M. \& Salimena, F.R.G. 2020. Verbenaceae no Parque Estadual do Pico do Itambé, Estado de Minas Gerais, Brasil. Hoehnea 47: e122020. http://dx.doi.org/10.1590/2236-8906$12 / 2020$.

ABSTRACT - (Verbenaceae from the Parque Estadual do Pico do Itambé, Minas Gerais State, Brazil). We present the floristic treatment for the Verbenaceae from the Parque Estadual do Pico do Itambé, located at the central portion of the Espinhaço Range, in Minas Gerais State. With a current extension of 4,696 ha., this Conservation Unit has the highest altitudes of the Espinhaço Range, with the Pico do Itambé ranging $2.060 \mathrm{~m}$. This conservation unit is considered an area of special biological importance, where the campos rupestres formations must be highlighted. After fieldwork and herbaria consultation we found six species of Verbenaceae distributed in three genera: Lantana camara L., Lantana lundiana Schauer, Lippia origanoides Kunth, Lippia pseudothea Schauer, Lippia rhodocnemis Mart. \& Schauer and Stachytarpheta itambensis S.Atkins, being the last two considered threatened of extinction. We provide descriptions, an identification key, photographs, and comments on taxonomy, geographic distribution, and preferential habitats, in order to contribute with the management and conservation of the species.

Keywords: campos rupestres, Cerrado, conservation, Espinhaço Range, taxonomy

RESUMO - (Verbenaceae no Parque Estadual do Pico do Itambé, Estado de Minas Gerais, Brasil). Apresentamos o tratamento florístico de Verbenaceae no Parque Estadual do Pico do Itambé, localizado na porção central da Cadeia do Espinhaço no Estado de Minas Gerais. Com área total de 4.696 ha, essa Unidade de Conservação apresenta o ponto de maior altitude da Cadeia do Espinhaço, o Pico do Itambé com $2.060 \mathrm{~m}$. Está inserida em uma área considerada de importância biológica especial, onde se destacam os campos rupestres. Após o trabalho de campo e a consulta em herbários foram encontradas seis espécies de Verbenaceae pertencentes a três gêneros: Lantana camara L., Lantana lundiana Schauer, Lippia origanoides Kunth, Lippia pseudothea Schauer, Lippia rhodocnemis Mart. \& Schauer e Stachytarpheta itambensis S.Atkins, as duas últimas consideradas ameaçadas de extinção. São fornecidas descrições, chave de identificação, fotografias e comentários sobre a taxonomia, distribuição geográfica e habitats preferencias, contribuindo com o manejo e a conservação das espécies. Palavras-chave: Cadeia do Espinhaço, campos rupestres, Cerrado, conservação, taxonomia

1. Universidade Federal de Juiz de Fora, Instituto de Ciências Biológicas, Campus Universitário, Rua José Lourenço Kelmer, s/n, São Pedro, 36036-900 Juiz de Fora, MG, Brasil

2. Universidade Federal do Rio de Janeiro, Departamento de Botânica, Museu Nacional, Quinta da Boa Vista, 20940-040 Rio de Janeiro, RJ, Brasil

3. Universidade Federal de Juiz de Fora, Departamento de Ciências Naturais, Rua Visconde de Mauá, 300, 36015-260 Juiz de Fora, MG, Brasil

4. Universidade Federal do Rio de Janeiro, Instituto de Biologia, Departamento de Botânica, Avenida Carlos Chagas Filho, 373, 21941590 Rio de Janeiro, RJ, Brasil

5. Autor para correspondência: pedrocardoso@ufrj.br 


\section{Introdução}

Verbenaceae reúne 34 gêneros e cerca de 800 espécies distribuídas predominantemente na Região Neotropical, tendo seu principal centro de diversidade nas regiões subtropicais e subáridas da América do Sul (Atkins 2004, Marx et al. 2010, Sanders 2001). O Brasil destaca-se com a maior representatividade da família, sendo registrados 15 gêneros e aproximadamente 290 espécies, das quais mais de 190 são endêmicas, encontradas principalmente no Cerrado (BFG 2018). Nesse Domínio, Lippia L. e Stachytarpheta Vahl. são os gêneros mais ricos, compreendendo diversas espécies raras e ameaçadas de extinção (Salimena et al. 2009, 2013, 2014).

As espécies de Verbenaceae apresentam hábito desde herbáceo até arbóreo, sendo mais frequentes espécies arbustivas e mais raramente lianas. Possuem ramos cilíndricos ou tetragonais, folhas simples, opostas ou verticiladas, raro alternas, frequentemente com margem crenada ou serreada, com inflorescências racemosas, terminais ou axilares; brácteas verdes ou róseas; flores monoclinas ou diclinas, sésseis ou pediceladas, zigomorfas, raro actinomorfas; cálice gamossépalo, tubuloso ou campanulado; corola gamopétala, 4-5-mera; estames 4-5, geralmente didínamos, ou 2 férteis e 2 estaminódios; gineceu 2-4 carpelar, 1-carpelar por aborto, ovário súpero, óvulos 1 por lóculo. Fruto do tipo drupa ou esquizocarpo (Atkins 2004).

A Cadeia do Espinhaço é uma das principais formações montanhosas do território brasileiro com mais de 1.000 $\mathrm{km}$ de extensão na direção norte-sul, apresentando seu limite setentrional na Serra da Jacobina, Estado da Bahia $\left(10^{\circ} 00^{\prime} \mathrm{S}\right)$, e meridional na Serra de Ouro Branco, Estado de Minas Gerais ( $21^{\circ} 25^{\prime}$ 'S). Sua extensão longitudinal varia aproximadamente entre 50 e $100 \mathrm{~km}\left(40^{\circ} 10^{\prime}-44^{\circ} 30^{\prime} \mathrm{W}\right)$ e as altitudes de 700 a $2.060 \mathrm{~m}$, sendo o Pico do Itambé, localizado na porção mineira, o ponto culminante (Moreira 1977, Derby 1906, Almeida-Abreu \& Renger 2002, Gontijo 2008, Chaves et al. 2012). Representa um importante centro de diversidade biológica da Região Neotropical, possuindo uma vegetação bastante heterogênea, composta por um mosaico de fitofisionomias, onde se destacam os campos rupestres como elemento característico (Giulietti et al. 1997, 2000, Colli-Silva et al. 2019). Nesses ambientes, vários gêneros de Asteraceae, Ericaceae, Lamiaceae, Melastomataceae e Verbenaceae ou mesmo famílias como Velloziaceae, Eriocaulaceae e Xyridaceae apresentam uma alta taxa de endemismo (Lohmann \& Pirani 1996, Costa 2005, Giulietti et al. 1997, Rapini et al. 2008).

O Pico do Itambé que se destaca na paisagem da Cadeia do Espinhaço atraiu a atenção e visitas de botânicos desde o século XIX. Em junho de 1818, os naturalistas Johann Baptiste von Spix e Carl Friendrich Phillip von Martius visitaram o Pico do Itambé e relataram, pela primeira vez, seus aspectos geomorfológicos e fitofisionômicos, revelando uma grande diversidade de ambientes (Chaves et al. 2012). Com o intuito de conservar a biodiversidade desse local e das áreas adjacentes, em 21 de janeiro de 1998, foi criado o Parque Estadual do Pico do Itambé (PEPI), através do Decreto ${ }^{0} 39.398$ do Governo Estadual de Minas Gerais (SEMAD 2004). O Parque está localizado em uma área considerada de importância biológica especial para a conservação da biodiversidade em Minas Gerais (Drummond et al. 2005) e reconhecida pela UNESCO como "Reserva da Biosfera Mundial" (Pereira et al. 2015).

Embora diversas espécies novas tenham sido descobertas na área do Pico do Itambé (p.ex., Agalinis itambensis V.C.Souza \& S.I.Elias, Ditassa itambensis Rapini, Griffinia itambensis Ravenna, Lapanthus itambensis (Versieux \& Leme) Louzada \& Versieux, Stachytarpheta itambensis S.Atkins e Xyris itambensis Kral \& Wand.), a flora do Parque ainda permanece praticamente desconhecida, com apenas uma listagem para Bromeliaceae (Versieux 2008). Desta forma, este estudo teve o objetivo de ampliar o conhecimento florístico e contribuir com o manejo e conservação das espécies ocorrentes no PEPI, através do tratamento taxonômico para Verbenaceae. São fornecidas descrições, chave de identificação, fotografias e comentários taxonômicos, ecológicos e de distribuição geográfica para as espécies.

\section{Material e Métodos}

O Parque Estadual do Pico do Itambé (PEPI) situa-se na região alta do Alto Vale do Jequitinhonha, na porção central da Cadeia do Espinhaço no Estado de Minas Gerais. Possui 4.696 hectares, abrangendo parte dos municípios de Serro (930 ha), Serra Azul de Minas (840 ha) e Santo Antônio do Itambé (2.926 ha). A vegetação está representada predominantemente por formações campestres (campo rupestre e campo limpo) incluindo também formações savânicas (cerrado típico, cerrado ralo e cerrado rupestre) e floresta estacional semidecidual (figura 1). Compreende numerosas cachoeiras e muitas nascentes de drenagens das bacias dos rios Jequitinhonha e Doce. O regime climático da região é tipicamente tropical, ocorrendo uma estação chuvosa e outra seca, com precipitação média anual variando entre 1.250 e $1.550 \mathrm{~mm}$ e temperatura entre 18 e $19^{\circ} \mathrm{C}$. Está interligado geograficamente com a APA Estadual das Águas Vertentes e o Monumento Natural Estadual da Várzea do Lajeado e Serra do Raio (Neves et al. 2005, SEMAD 2004).

Para o tratamento florístico foram analisadas as coleções de Verbenaceae depositadas nos Herbários CESJ, NY, RB e UB (acrônimos segundo Thiers 2020), consultas aos bancos de dados Reflora (floradobrasil.jbrj.gov.br) e Specieslink (splink.cria.org.br), e realizada uma expedição ao campo para observação e/ou coletas das espécies analisadas nas coleções depositadas nos Herbários. Os espécimes foram identificados por meio de literatura especializada e consulta aos tipos nomenclaturais disponíveis no JSTOR (https:// plants.jstor.org/). A terminologia morfológica segue Harris \& Harris (2003), Atkins (2005), Gonçalves \& Lorenzi (2007), O'Leary et al. (2012). As informações sobre fenologia e habitat foram obtidas com base nas observações de campo e nas etiquetas de coleta dos espécimes. 

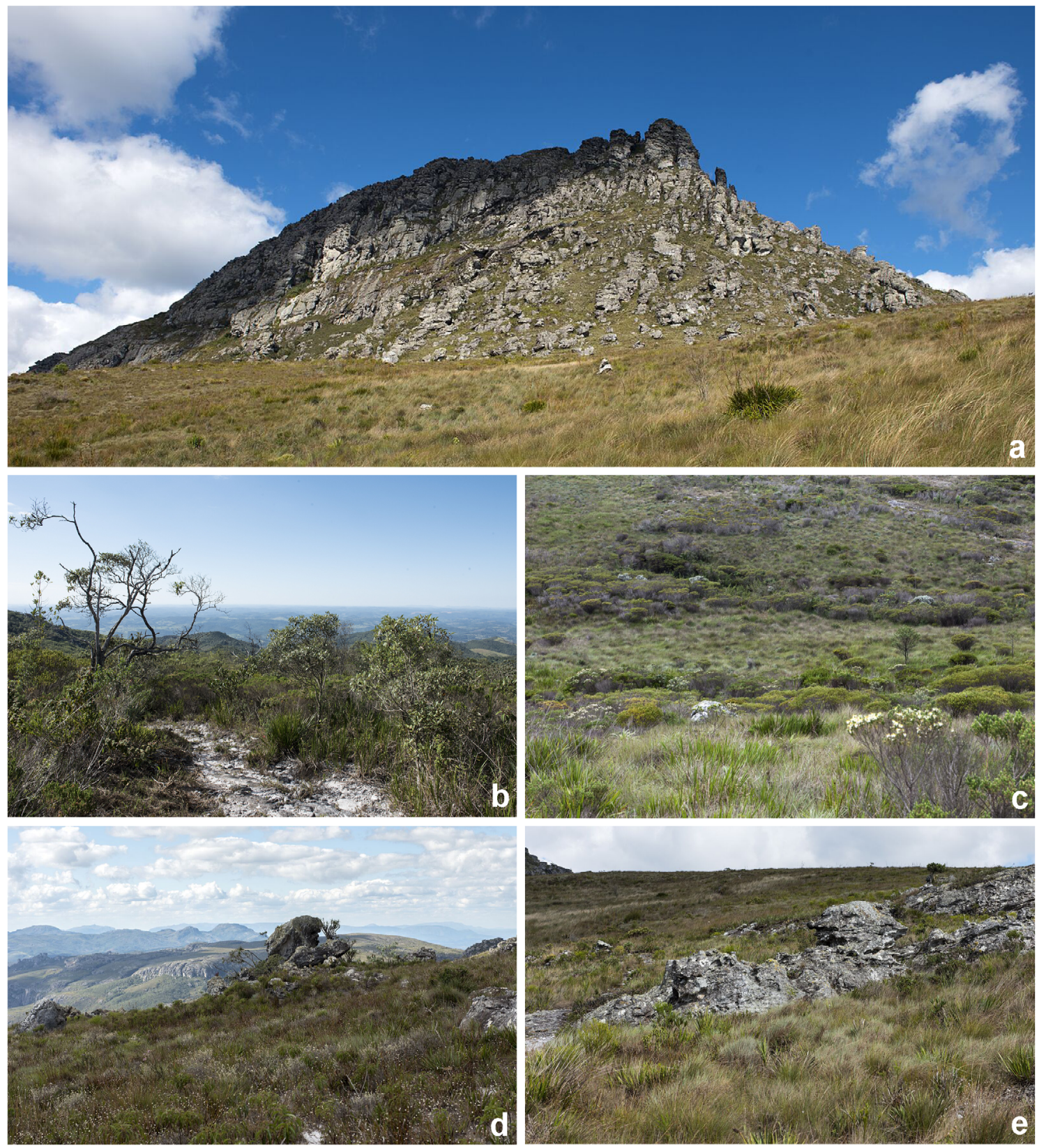

Figura 1. Fitofisionomias do Parque Estadual do Pico do Itambé, Estado de Minas Gerais, Brasil. a. Pico do Itambé, visto pelo município de Serro, cercado por campos rupestres com predominio de gramíneas. b. campo rupestre com solo arenoso. c. campo úmido na base do Pico, município de Santo Antônio do Itambé. d-e. campos rupestres com afloramentos quartziticos no entorno do Pico do Itambé.

Figure 1. Phytophysiognomies of the Parque Estadual do Pico do Itambé, Minas Gerais State, Brazil. a. Pico do Itambé, seen by the municipality of Serro, surrounded by campos rupestres with predominance of grasses. b. campo rupestre with sandy soil. c. campo úmido at the base of Pico, municipality of Santo Antônio do Itambé. d-e. campos rupestres with quartzite outcrops in the surroundings of Pico do Itambé.

\section{Resultados e Discussão}

Verbenaceae está representada no Parque Estadual do Pico do Itambé (PEPI) por seis espécies incluídas em três gêneros: Lantana camara L., Lantana lundiana Schauer, Lippia origanoides Kunth, Lippia pseudothea Schauer, Lippia rhodocnemis Mart. \& Schauer e Stachytarpheta itambensis S.Atkins. Todas as espécies foram encontradas na área de estudo em campo rupestre, exceto Lantana camara que ocorre nas encostas com florestas secundárias e campos cobertos de samambaias.

Dentre as seis espécies registradas, Lantana camara é considerada uma espécie ruderal e invasora, com ampla distribuição no mundo (Lorenzi 1991, Silva 1999), Lippia 
origanoides ocorre ao longo da Região Neotropical (O’Leary et al. 2012), e as demais espécies são endêmicas do Brasil (BFG 2018). Lantana lundiana ocorre em campo rupestre e floresta ciliar nos domínios do Cerrado e Floresta Atlântica na Região Sudeste, enquanto Lippia pseudothea, Lippia rhodocnemis e Stachytarpheta itambensis são restritas aos campos rupestres da Cadeia do Espinhaço no Estado de Minas Gerais, sendo as duas últimas consideradas ameaçadas de extinção, merecendo atenção especial em ações de conservação (Salimena et al. 2013, 2014, BFG 2018).

Em comparação com outras áreas situadas no domínio do Cerrado no Estado de Minas Gerais, o PEPI compartilha com a Serra do Cipó duas espécies (Salimena-Pires \& Giulietti 1998), ao passo que nenhuma espécie em comum é observada para o Parque Estadual de Grão Mogol (Salimena \& Silva 2009) e Parque Nacional da Serra da Canastra (Cardoso et al. 2020). Já em comparação com outras áreas de campos rupestres no Estado de Minas Gerais, porém inseridas na Floresta Atlântica, compartilha, respectivamente, uma e duas espécies com a Serra Negra (Cardoso et al. 2018) e Parque Estadual do Ibitipoca (Cruz \& Salimena 2017) (Tabela 1). De modo geral, são comuns entre as diferentes áreas apenas espécies de ampla distribuição (Tabela 1), concordando com outros trabalhos que mostram que Verbenaceae possui uma alta taxa de endemismo (Salimena-Pires \& Giulietti 1998, Salimena \& Silva 2009, Cruz \& Salimena 2017, Cardoso et al. 2018, 2019).

No entorno do PEPI ocorrem Lippia hermannioides Cham., Lippia lacunosa Mart. \& Schauer, Lippia rubella (Moldenke) T.R.S.Silva \& Salimena e Stachytarpheta harleyi S.Atkins. Estas espécies são comuns nos campos rupestres da Cadeia do Espinhaço e até o momento não foram encontradas dentro dos limites do parque. É importante ressaltar que Lippia violacea Moldenke, descrita para a Serra Quebrada, na região entre Capivari e Pico do Itambé, conhecida somente pela coleção-tipo, trata-se de um sinônimo de Lippia rubella (BFG 2018), apresentando o único registro nas proximidades do parque no ano de 1942, nunca mais coletada nesta área.

Chave de Identificação para as espécies de Verbenaceae do Parque Estadual do Pico do Itambé

1. Inflorescências terminais, espiciformes; corola azul, androceu formado por 2 estames férteis e 2 estaminódios

6. Stachytarpheta itambensis

1. Inflorescências axilares, hemisféricas, globosas ou tetrásticas, corola branca, lilás, rósea, vermelha, amarela ou alaranjada, androceu formado por 4 estames férteis

2. Ramos aculeados; corola vermelha, amarela ou alaranjada

1. Lantana camara

2. Ramos inermes; corola lilás, rósea ou branca

3. Ramos vilosos; lâmina foliar com base truncada, decurrente no pecíolo, margem serreada; brácteas com ápice aristado; fruto drupa 2. Lantana lundiana

3. Ramos glandulosos, estrigoso-glandulosos ou hirsuto-glandulosos; lâmina foliar com base cuneada ou obtusa, margem crenada; brácteas com ápice agudo ou obtuso; fruto esquizocarpo

4. Inflorescências tetrásticas, 2-4 por axila; brácteas ca. 0,3 cm compr. foliáceas; corola branca.

3. Lippia origanoides

4. Inflorescências globosas, 1 por axila; brácteas iguais ou maiores que $0,7 \mathrm{~cm}$ compr., membranáceas; corola rósea 5. Folhas sésseis, espatuladas, base cuneada, face adaxial glandulosa, tricomas glandulares pedicelados...

4. Lippia pseudothea

5. Folhas pecioladas, oval-elípticas a oblongo-elípticas, base obtusa, face adaxial velutina

5. Lippia rhodochnemis

\section{Lantana camara L., Sp. pl. 2:627. 1753.}

Figura 2 a

Arbustos ca. 0,7 m alt., ramos aculeados, eretos, tetragonais, esparsamente hirsutos, tricomas glandulares sésseis presentes. Folhas opostas, pecioladas, lâmina 4-9 $\times$ 3-5,4 cm, elíptica a largo-ovada, cartácea, levemente discolor, ápice agudo-acuminado, base obtusa a atenuada, margem crenado-serreada, ciliada, face adaxial estrigosa, nervuras impressas, face abaxial pubescente a hirsuta, nervuras proeminentes. Inflorescências hemisféricas, 1-1,3 cm compr., 1 por axila, raque compacta, não alongada na frutificação, pedúnculo 1,3-3 cm compr., hirsuto-glanduloso; brácteas ca. $0,5 \mathrm{~cm}$ compr., lanceoladas, livres, dispostas espiraladamente, foliáceas, verdes, face abaxial estrigoso-glandulosa, tricomas glandulares sésseis, ápice agudo, margem ciliada; cálice ca. 0,2 cm compr., tubuloso, 4-laciniado, membranáceo, verde, externamente pubescente, não acrescente no fruto; corola 0,8-1 cm compr., zigomorfa, hipocrateriforme, 2-labiada, vermelha, alaranjada ou amarela, externamente pubescenteglandulosa; estames 4, férteis, didínamos, inseridos na metade do tubo da corola, tecas paralelas; ovário 2-locular, lóculos 1-seminado, estigma oblíquo. Fruto drupa, ca. $0,4 \mathrm{~cm}$ compr., imaturo verde, maduro preto, superfície externa rugosa. 
Tabela 1. Comparação entre listagens de Verbenaceae do Estado de Minas Gerais, Brasil (incluindo áreas situadas no Cerrado e áreas de campo rupestre da Floresta Atlântica) e de espécies compartilhadas com o Parque Estadual do Pico do Itambé (PEPI).

Table 1. Comparison among lists of Verbenaceae from Minas Gerais State, Brazil (including areas located in the Cerrado and areas of campo rupestre in the Atlantic Forest) and the shared species with the Parque Estadual do Pico do Itambé (PEPI).

\begin{tabular}{lccc}
\hline Área & Domínio Fitogeográfico & Total de espécies & $\begin{array}{c}\text { Espécies compartilhadas } \\
\text { com o PEPI }\end{array}$ \\
\hline $\begin{array}{l}\text { Serra do Cipó (Sálimena-Pires } \\
\text { \& Giulietti 1998) }\end{array}$ & Cerrado & 13 & $\begin{array}{c}\text { Lantana lundiana } \text { e Lippia } \\
\text { origanoides }\end{array}$ \\
$\begin{array}{l}\text { Parque Estadual de Grão Mogol } \\
\text { Salimena \& Silva 2009) }\end{array}$ & Cerrado & 13 & - \\
$\begin{array}{l}\text { Parque Nacional da Serra da Canastra } \\
\text { (Cardoso } \text { et al. 2020) }\end{array}$ & Cerrado & 8 & - \\
$\begin{array}{l}\text { Serra Negra (Cardoso et al. 2018) } \\
\begin{array}{l}\text { Parque Estadual do Ibitipoca } \\
\text { (Cruz \& Salimena 2019) }\end{array}\end{array}$ & Floresta Atlântica & 5 & Lippia origanoides \\
\hline
\end{tabular}

Lantana camara é nativa da América tropical e subtropical, sendo considerada uma espécie ruderal, cultivada para fins ornamentais, e invasora em diversas partes do mundo (Lorenzi 1991, Silva 1999). No Brasil, é a espécie de Lantana com a distribuição mais ampla, encontrada em todos os Estados e domínios fitogeográficos (BFG 2018). Caracteriza-se por apresentar ramos aculeados; folhas com ápice agudo-acuminado; pedúnculos menores que as folhas; inflorescências não alongadas na frutificação; brácteas lanceoladas e corola vermelha, alaranjada ou amarela. No PEPI foi encontrada em ambientes antropizados, nas encostas de florestas secundárias e campos cobertos de samambaias. Coletada com flores e frutos em fevereiro.

Material examinado: BRASIL. MinAS GERAIS. Santo Antônio de Itambé, sudeste do Pico do Itambé, 9-II-1972, W.R. Anderson et al. 35661 (NY, UB); Santo Antônio de Itambé, sudeste do Pico do Itambé, 9-II-1972, W.R. Anderson et al. 35739 (NY, UB).

2. Lantana lundiana Schauer, Prodr. [A. P. de Candolle] 11: 605.1847

Figura $2 \mathrm{~b}$

Arbustos 0,6-2 $\mathrm{m}$ alt., ramos inermes, eretos, tetragonais, vilosos. Folhas opostas, pecioladas, lâmina 2-5 $\times 1-2 \mathrm{~cm}$, ovada, cartácea, fortemente discolor, ápice agudo, base truncada, decurrente no pecíolo, margem serreada, ciliada, face adaxial densamente estrigosa, fortemente bulada, nervuras impressas, face abaxial vilosa, tricomas glandulares sésseis abundantes, foveolada, nervuras proeminentes. Inflorescências hemisféricas, $1-1,2 \mathrm{~cm}$ compr., 1 por axila, raque compacta, alongada até $3,5 \mathrm{~cm}$ compr. na frutificação, pedúnculo 2-4,3 cm compr., viloso; brácteas $0,5-0,8 \mathrm{~cm}$ compr., ovadas, livres, dispostas espiraladamente, foliáceas, verdes a vináceas, face abaxial vilosa, tricomas glandulares sésseis abundantes, ápice aristado, margem ciliada; cálice ca. 0,15 cm compr., tubuloso, 4-laciniado, membranáceo, verde, externamente viloso, tricomas glandulares sésseis, acrescente no fruto; corola 1-1,1 cm compr., zigomorfa, hipocrateriforme, 2-labiada, lilás, fauce amarela, externamente viloso-glandulosa, tricomas glandulares sésseis; estames 4, férteis, didínamos, inseridos na metade do tubo da corola, tecas paralelas; ovário 2-locular, lóculos 1-seminado, estigma oblíquo. Fruto drupa, ca. 0,4 cm compr., imaturo verde, maduro vináceo, superfície externa rugosa.

Lantana lundiana é endêmica do Cerrado e Floresta Atlântica da Região Sudeste do Brasil, encontrada nos campos rupestres e matas ciliares (Silva 1999, BFG 2018). Caracteriza-se por apresentar ramos inermes, vilosos; face adaxial da lâmina foliar fortemente bulada, face abaxial vilosa e brácteas ovadas, verdes a vináceas, com ápice aristado. No PEPI, ocorre no campo rupestre em afloramentos quartzíticos. Coletada com flores e frutos em fevereiro, abril e maio.

Material examinado: BRASIL. Minas GeraIs. Santo Antônio do Itambé, Pico do Itambé, 3-V-1942, M. Magalhães 1763 (UB); Pico do Itambé, 4-IV-1982, L. Rossi et al. CFCR 3003 (K, SPF); Pico do Itambé, 9-II-1972, W.R. Anderson et al. 35715 (NY, UNB); Pico do Itambé, 12-II-1972, W.R. Anderson et al. 35858 (K, NY, UNB), Pico do Itambé, 7-IV-1998. V.C. Souza et al. 21035 (ESA, RB); Pico do Itambé, 10-II-2009, J.G. Rando et al. 855 (HUEFS, SPF); Pico do Itambé, 8-IV-2010, G.O. Romão et al. 2579 (ESA, RB); Serro, 31-V-2019, F.R.G. Salimena \& P.H. Nobre 4029 (CESJ). 
3. Lippia origanoides Kunth, Nov. Gen. Sp. 2: 267. 1817 [1818].

Figura $2 \mathrm{c}$

Arbustos 0,4-2 m alt., fortemente aromáticos, ramos inermes, eretos, cilíndricos, hirsuto-glandulosos, tricomas glandulares sésseis. Folhas opostas, pecioladas, lâmina 0,4$0,7 \times 0,2-0,3 \mathrm{~cm}$, ovada ou oblonga, cartácea, levemente discolor, ápice obtuso a arredondado, base cuneada a obtusa, margem crenada, ciliada, face adaxial serícea, bulada, nervuras impressas, face abaxial densamente vilosa, nervuras proeminentes, tricomas glandulares sésseis abundantes em ambas as faces. Inflorescências tetrásticas $0,4-0,8$ $\mathrm{cm}$ compr., 2-4 por axila, raque compacta, não alongada na frutificação, pedúnculo $0,4-0,5 \mathrm{~cm}$ compr., hirsutoglanduloso, tricomas glandulares sésseis; brácteas ca. $0,3 \mathrm{~cm}$ compr., ovadas, as basais conatas, as apicais livres, dispostas em 4 fileiras, foliáceas, verdes, face abaxial densamente hirsuto-glandulosa, tricomas glandulares sésseis, ápice agudo, margem ciliada; cálice ca. $0,2 \mathrm{~cm}$ compr., tubuloso, 4-laciniado, membranáceo, verde, externamente hirsutoglanduloso, tricomas glandulares sésseis, acrescente no fruto; corola 0,3-0,5 cm compr., zigomorfa, hipocrateriforme, 2-labiada, branca, externamente glabra no terço inferior, hirsuto-glandulosa no terço superior, tricomas glandulares sésseis; estames 4, férteis, didínamos, inseridos na metade do tubo da corola, tecas paralelas; ovário 2-locular, lóculos 1 -seminado, estigma oblíquo. Fruto esquizocarpo, ca. 0,2 $\mathrm{cm}$ compr., castanho, superfície externa lisa.

Lippia origanoides é amplamente distribuída na Região Neotropical (O'Leary et al. 2012). No Brasil, é encontrada na Floresta Amazônica, Caatinga, Cerrado e Floresta Attântica (BFG 2018). Caracteriza-se pelas inflorescências tetrásticas, numerosas por axila; brácteas basais conatas, apicais livres e corola branca. Esta espécie possui 28 sinônimos, apresentando alto polimorfismo foliar e indumento diverso (O'Leary et al. 2012). Os espécimes encontrados na área de estudo apresentam folhas diminutas, ovadas ou oblongas, ápice obtuso a arredondado, base cuneada ou obtusa, margem crenada, face adaxial serícea, face abaxial densamente vilosa, com tricomas glandulares sésseis em ambas as faces. No PEPI, ocorre nos campos rupestres entre afloramentos em solo arenoso. Coletada com flores e frutos em maio.

Material examinado: BRASIL. MinAs GeraIs. Serro, Pico do Itambé, 3-V-1942, M. Magalhães 1742 (CESJ, NY), Pico do Itambé, 31-V-2019, F.R.G. Salimena \& P.H. Nobre 4024 (CESJ).

4. Lippia pseudothea Schauer, Prodr. [A. P. de Candolle] 11: 582.1847

Figura $2 \mathrm{~d}$

Arbustos ca. 1,2 m alt., fortemente aromáticos, viscosos, ramos inermes, eretos, cilíndricos, glandulosos, tricomas glandulares pedicelados. Folhas opostas ou 3 -verticiladas, sésseis, lâmina 2,5-4 × 1-2 cm, espatulada, coriácea, levemente discolor, ápice obtuso, base cuneada, margem crenada, ciliada, face adaxial glandulosa, tricomas glandulares pedicelados, nervuras impressas, face abaxial glandulosa, tricomas glandulares pedicelados, nervuras proeminentes, hirsutas. Inflorescências globosas, 1-1,3 cm compr., 1 por axila, raque compacta, não alongada na frutificação, pedúnculo 1,5-2 cm compr., glanduloso, tricomas glandulares pedicelados; brácteas $0,7-1 \mathrm{~cm}$ compr., largo-ovadas, livres, dispostas espiraladamente, membranáceas, verde-rosadas com ápice vináceo, face abaxial hirsuto-glandulosa, tricomas glandulares pedicelados, ápice agudo, margem ciliada; cálice ca. 0,2 cm compr., tubuloso, 4-laciniado, membranáceo, verde, externamente hirsuto-glanduloso, tricomas glandulares pedicelados, acrescente no fruto; corola $0,6-0,7 \mathrm{~cm}$ compr., zigomorfa, hipocrateriforme, 2-labiada, rósea, externamente glabra no terço inferior, pubescente-glandulosa no terço superior, tricomas glandulares sésseis; estames 4, férteis, didínamos, inseridos no terço inferior do tubo da corola, tecas paralelas; ovário 2 locular, lóculos 1-seminado, estigma oblíquo. Fruto esquizocarpo, 0,15-0,2 cm compr., castanho, superfície externa lisa.

Lippia pseudothea é endêmica da Cadeia do Espinhaço no Estado de Minas Gerais (BFG 2018). Caracteriza-se por apresentar tricomas glandulares pedicelados abundantes por toda planta, folhas sésseis, espatuladas e brácteas verderosadas com ápice vináceo. No PEPI, é encontrada em campo rupestre, entre afloramentos rochosos. Coletada com flores e frutos em maio.

Material examinado: BRASIL. MinAs GeraIs. Serro, 31-V2019, F.R.G. Salimena \& P.H. Nobre 4025 (CESJ).

Material adicional examinado: BRASIL. MINAS GERAIS. Diamantina, 4-V-1931, Y. Mexia 5749 (NY); Diamantina, 30-VIII-1981, A.M. Giulietti et al. CFCR 1804 (K, SPF).

5. Lippia rhodocnemis Mart. \& Schauer, Prodr. [A. P. de Candolle] 11: 592.1847

Figura $2 \mathrm{e}$

Arbustos 1-2 m alt., aromáticos, ramos inermes, eretos, cilíndricos, densamente velutino-glandulosos, tricomas glandulares sésseis e pedicelados. Folhas opostas, pecioladas, lâmina 2,5-6 × 1-3,4 cm, ovalelíptica a oblongo-elíptica, coriácea, fortemente discolor, ápice obtuso, base obtusa, margem crenada, ciliada, face adaxial velutina, fortemente bulada, nervuras impressas, face abaxial canescente-glandulosa, tricomas glandulares séssieis, foveolada, nervuras proeminentes. Inflorescências globosas, 1,5-2 cm compr., 1 por axila, raque compacta, levemente alongada na frutificação, pedúnculo 1,5-3,3 cm compr., hirsuto-glanduloso, tricomas glandulares sésseis e pedicelados; brácteas 1-1,5 cm compr., largo-ovadas, livres, dispostas espiraladamente, membranáceas, róseas a magentas, face abaxial pubérulo-glandulosa a esparsamente hirsuto-glandulosa, tricomas glandulares sésseis, ápice 

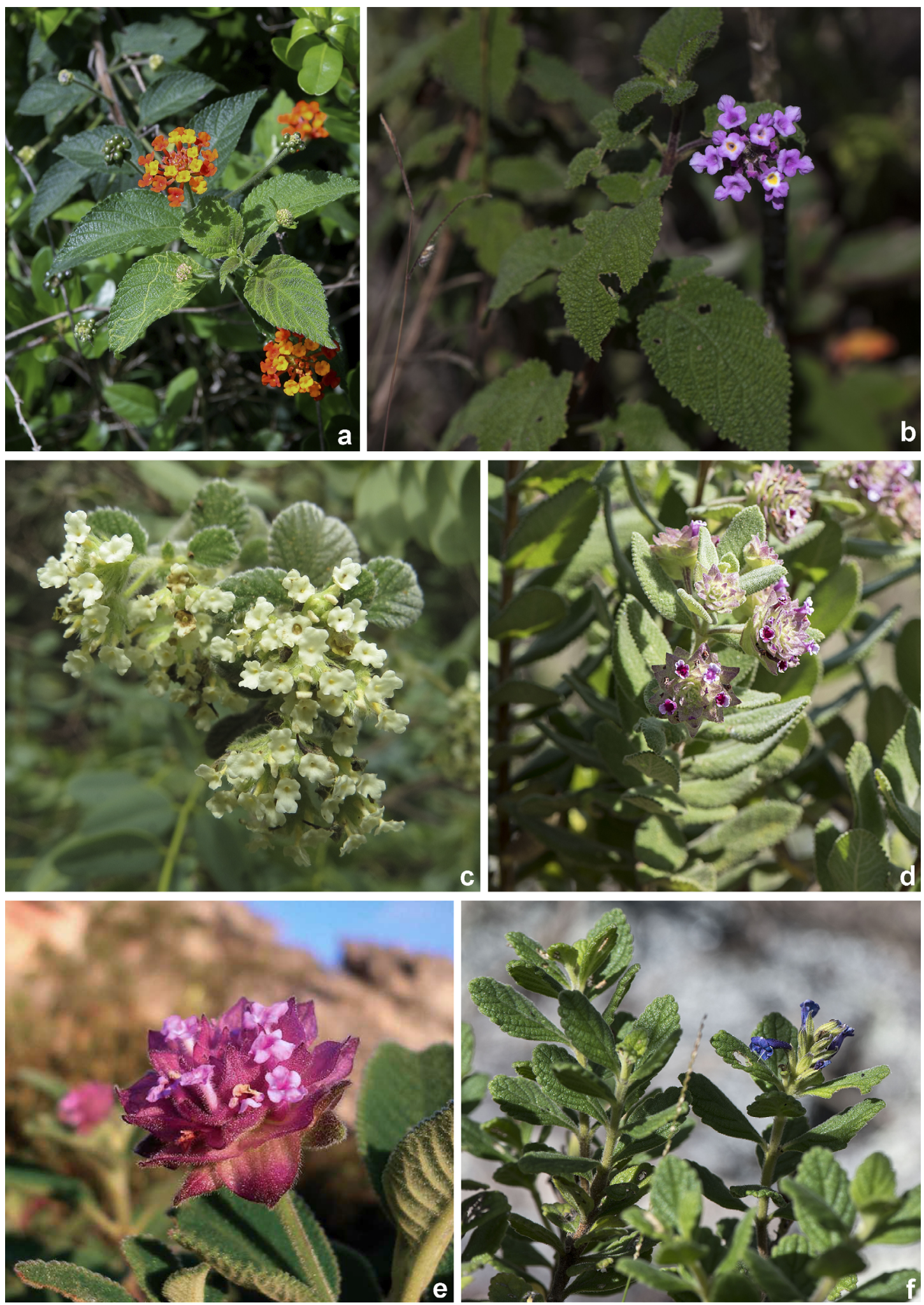

Figura 2. Espécies de Verbenaceae do Parque Estadual do Pico do Itambé, Estado de Minas Gerais, Brasil. a. Lantana camara L. b. Lantana lundiana Schauer. c. Lippia origanoides Kunth. d. Lippia pseudothea Schauer. e. Lippia rhodocnemis Mart. \& Schauer. f. Stachytarpheta itambensis S.Atkins. (fotos a: Mauricio Mercadante; b, d, f: Pedro Henrique Nobre; c: Maria Ignez Calhau; e: Luiz Menini Neto).

Figure 2. Species of Verbenaceae from the Parque Estadual do Pico do Itambé, Minas Gerais State, Brazil. a. Lantana camara L. b. Lantana lundiana Schauer. c. Lippia origanoides Kunth. d. Lippia pseudothea Schauer. e. Lippia rhodocnemis Mart. \& Schauer. f. Stachytarpheta itambensis S.Atkins. (Photos a: Mauricio Mercadante; b, d, f: Pedro Henrique Nobre; c: Maria Ignez Calhau; e: Luiz Menini Neto). 
agudo a obtuso, margem ciliada; cálice ca. $0,15 \mathrm{~cm}$ compr., tubuloso, 4-laciniado, membranáceo, verde, externamente densamente hirsuto-glanduloso, tricomas glandulares sésseis, acrescente no fruto; corola $0,6-0,9 \mathrm{~cm}$ compr., zigomorfa, hipocrateriforme, 2-labiada, rósea, fauce amarela, externamente glabra no terço inferior, hirsuto-glandulosa no terço superior, tricomas glandulares sésseis; estames 4, férteis, didínamos, inseridos no terço inferior do tubo da corola, tecas paralelas; ovário 2 locular, lóculos 1-seminado, estigma oblíquo. Fruto esquizocarpo, ca. 0,2 cm compr., castanho, superfície externa lisa.

Lippia rhodocnemis é endêmica da Cadeia do Espinhaço no Estado de Minas Gerais (BFG 2018). Assemelha-se a Lippia pseudothea, diferindo por apresentar folhas pecioladas, oval-elípticas a oblongo-elípticas, fortemente discolores e brácteas róseas a magentas de 1-1,5 cm compr. No PEPI, é encontrada em campo rupestre, somente na região do Pico do Itambé a $2.000 \mathrm{~m}$ de altitude em afloramento quartzítico, em solo arenoso. Coletada com flores e frutos em maio.

Material examinado: BRASIL. Minas GeraIs. Pico do Itambé, 5-V-1942, M. Magalhães 1815 (NY, UB).

Material adicional examinado: BRASIL. MINAS GeraIS. Felício dos Santos, 10-VI-2006, F.R.G. Salimena et al. 1385 (CESJ).

6. Stachytarpheta itambensis S.Atkins, Kew Bull. 60(2): 251. 2005

Figura $2 \mathrm{f}$

Arbustos, 0,4-1,5 m alt., ramos inermes, eretos, cilíndricos ou tetragonais, densamente estrigosos. Folhas opostas, pecioladas, lâmina 2-3,5 ×1-15 cm, ovada, cartácea, levemente discolor, ápice obtuso, base atenuada, margem inteira no terço basal, crenada em direção ao ápice, ciliada, face adaxial estrigosa, nervuras impressas, face abaxial viloso-estrigosa, nervuras proeminentes, nectários presentes. Inflorescências espiciformes, 1,5-2,4 cm compr., terminais, raque laxa; brácteas $0,4-0,5 \mathrm{~cm}$ compr., lanceoladas, livres, apressas ao cálice, dispostas alternadamente, foliáceas, verdes, face abaxial estrigosa, ápice agudo, margem ciliada; cálice ca. $1 \mathrm{~cm}$ compr., tubuloso, 4-laciniado, 1 seio adaxial, membranáceo, verde, externamente estrigoso, acrescente no fruto; corola ca. 1,5 cm compr., zigomorfa, hipocrateriforme, 5-lobada, azul, externamente pubérula-glandulosa, tricomas glandulares pedicelados; estames férteis 2, estaminódios 2 , inseridos no terço superior do tubo da corola, tecas divergentes; ovário 2-locular, lóculos 1-seminado, estigma capitado. Fruto esquizocarpo, ca. $0,5 \mathrm{~cm}$ compr., castanho, superfície externa reticulada.

Stachytarpheta itambensis é endêmica do Cerrado no Estado de Minas Gerais (BFG 2018). Caracteriza-se por apresentar inflorescências espiciformes; brácteas estrigosas, ápice agudo, cálice 4-laciniado com seio adaxial, estrigoso; corola ca. $1,5 \mathrm{~cm}$ compr., azul e androceu formado por dois estames férteis e dois estaminódios. No PEPI, ocorre em afloramentos quartzíticos na subida para o Pico. Coletada com flores e frutos em fevereiro, maio, julho e agosto.

Material examinado: BRASIL. Minas Gerais. Pico do Itambé, 13-II-1972, W.R. Anderson et al. 35918 (NY, UB, US); Santo Antônio do Itambé, Pico do Itambé, 9-VIII1972, G. Hatschbach 30115 (MBM, US); Santo Antônio do Itambé, Pico do Itambé, 16-VII-1987, D.C. Zappi et al. CFCR 11245 (SPF), Serro, 31-V-2019, F.R.G. Salimena \& P.H. Nobre 4026 (CESJ).

\section{Agradecimentos}

Agradecemos à Mariana Gontijo, Gerente do Parque Estadual do Pico do Itambé, pelo apoio; ao Instituto Estadual de Florestas pelo apoio logístico, ao Adão da Conceição Rodrigues pelo acompanhamento no campo; à Maria Ignez Calhau e ao Mauricio Mercadante, pela cessão das fotografias. O presente trabalho foi realizado com apoio do $\mathrm{CNPq}$, Conselho Nacional de Desenvolvimento Científico e Tecnológico - Brasil.

\section{Literatura citada}

Almeida-Abreu, P. A. \& Renger, F. E. 2002. A Serra do Espinhaço Meridional: um orógeno de colisão do Mesoproterozóico. Revista Brasileira de Geociências 32: 1-14.

Atkins, S. 2004. Verbenaceae. In: K. Kubtzki \& J.W. Kadereit (eds.). The families and genera of vascular plants. Springer-Verlag 7: 449-468.

Atkins, S. 2005. The genus Stachytarpheta (Verbenaceae) in Brazil. Kew Bulletin 60: 161-272.

BFG (The Brazil Flora Group) 2018. Brazilian Flora 2020: Innovation and collaboration to meet Target 1 of the Global Strategy for Plant Conservation (GSPC). Rodriguésia 69: 1513-1527.

Cardoso, P. H., Cabral, A., Valério, V. I. R. \& Salimena, F. R. G. 2018. Verbenaceae na Serra Negra, Minas Gerais, Brasil. Rodriguésia 69: 777-786.

Cardoso, P. H., Cabral, A., Santos-Silva, F. \& Salimena, F. R. G. 2020. Verbenaceae no Parque Nacional da Serra da Canastra, Minas Gerais, Brasil. Rodriguésia, 71: 1-11.

Cardoso, P. H., Santos-Silva, F., Menini Neto, L. \& Salimena, F. R. G. 2019. Verbenaceae no Parque Nacional do Caparaó, Serra da Mantiqueira, Brasil. Hoehnea 46(3): 1-12.

Chaves, M. L. D. S. C., Andrade, K. W. \& Benitez, L. 2012. Pico do Itambé, Serra do Espinhaço, MG. Imponente relevo residual na superfície de erosão Gondwana. Sítios Geológicos e Paleontológicos do Brasil. Disponível em http://sigep.cprm.gov.br/sitio057/sitio057.pdf http:// sweetgum.nybg.org/ih/ (acesso em 16-I-2020).

Colli-Silva, M., Vasconcelos, T. N. \& Pirani, J. R. 2019. Outstanding plant endemism levels strongly support the recognition of campo rupestre provinces in mountaintops of eastern South America. Journal of Biogeography 46: 1723-1733. 
Costa, F. N. 2005. Campos Rupestres, In: A. C. Silva, L.C.V.S.F. Pedreira \& P. A. Almeida-Abreu (eds.). Serra do Espinhaço Meridional: paisagens e ambientes. O Lutador, Belo Horizonte, pp. 139-145.

Cruz, L.V.V. \& Salimena, F.R.G. 2017. Verbenaceae J.St.Hil. do Parque Estadual do Ibitipoca, Minas Gerais, Brasil. Boletim de Botânica da Universidade de São Paulo 35: 65-74.

Derby, D. A. 1906. The Serra do Espinhaço, Brazil. Journal of Geology 14: 374-401.

Drummond, G. M., Martins, C. S., Machado, A. B. M., Sebaio, F. A. \& Antonini, Y. 2005. Biodiversidade em Minas Gerais: Um atlas para sua conservação. 2a ed. Fundação Biodiversitas, Belo Horizonte.

Giulietti, A. M., Pirani, J. R. \& Harley, R. 1997. Espinhaço Range region, eastern Brazil. In: S. D. Davis, V. H. Heywood, O. Herrera-MacBryde, J. Villa-Lobos \& A. C. Hamilton (eds.). Centres of Plant Diversity IUCN publications, Cambrige, U.K 3: 397-404.

Giulietti, A. M., Harley, R. M., Queiroz, L. P. D., Wanderley, M. G. L. \& Pirani, J. R. 2000. Caracterização e endemismos nos campos rupestres da Cadeia do Espinhaço. In: T. B. Cavalcanti \& B. M. T. Walter (eds). Tópicos Atuais em Botânica. Embrapa Recursos Genéticos e Biotecnologia, Brasília, Brasil, pp 311-318.

Gonçalves, E.G. \& Lorenzi, H. 2007. Morfologia vegetal: organografia e dicionário ilustrado de morfologia das plantas vasculares. Instituto Plantarum, Nova Odessa.

Gontijo, B. M. 2008. Uma geografia para a Cadeia do Espinhaço. Megadiversidade: 7-14.

Harris, J.G. \& Harris, M.W. 2003. Plant identification terminology: an illustrated glossary. 2ed. Spring Lake Publ., Spring Lake.

Lohmann, L. G. \& Pirani, J. R. 1996. Tecomeae (Bignoniaceae) da Cadeia do Espinhaço, Minas Gerais e Bahia, Brasil. Acta Botanica Brasilica 10: 103-138.

Lorenzi, H. 1991. Plantas daninhas do Brasil: terrestres, aquáticas, parasitas, tóxicas e medicinais. 2 ed. Editora Plantarum, Nova Odessa.

Marx, H., O'Leary, N., Yuan, Y., Lu-Irving, P., Tank, D., Múlgura, M. E. \& Olmstead, R. 2010. A molecular phylogeny and classification of Verbenaceae. American Journal of Botany 97: 1647-1663.

Moreira, A. N. 1977. Relevo. In: IBGE. Geografia do Brasil. Região Nordeste. IBGE, Rio de Janeiro, 2: 1-45.

Neves, S. C., Almeida-Abreu, P. A., Fraga, L. M. S. 2005. Fisiografia. In: A. C. Silva, L.C.V.S.F. Pedreira \& P. A. Almeida-Abreu (eds.). Serra do Espinhaço Meridional: paisagens e ambientes. O Lutador, Belo Horizonte, pp. 47-58.
O’Leary, N., Denham, S. S., Salimena, F. \& Múlgura, M. E. 2012. Species delimitation in Lippia section Goniostachyum (Verbenaceae) using the phylogenetic species concept. Botanical Journal of the Linnean Society 170: 197-219.

Pereira, E. O., Gontijo, B. M. \& Campos-Abreu, L. G. Á. 2015. As ecorregiões da reserva da biosfera da serra do espinhaço: elementos para o fortalecimento da conservação da biodiversidade. Caderno de Geografia 25: 18-33.

Rapini, A., Ribeiro, P. L., Lambert, S. \& Pirani, J.R. 2008. A flora dos campos rupestres da Cadeia do Espinhaço. Megadiversidade 4: 16-24.

Salimena-Pires, F. R. G. \& Giulietti, A. M. 1998. Flora da Serra do Cipó, Minas Gerais: Verbenaceae. Boletim de Botânica da Universidade de São Paulo 17: 155-186.

Salimena, F. R. G., França, F. \& Silva, T. R. S. 2009. Verbenaceae. In: A. M. Giulietti, A. Rapini, M. J. G. Andrade, L. P. Queiroz \& J. M. C.Silva (eds.) Plantas raras do Brasil. Conservação Internacional, Belo Horizonte, pp. 399-405.

Salimena \& Silva, T.R.S. 2009. Flora de Grão-Mogol, Minas Gerais: Verbenaceae. Boletim de Botânica da Universidade de São Paulo 27: 119-126.

Salimena, F. R. G., Kutschenko, D. C., Monteiro, N. P. \& Mynssen, C. 2013. Verbenaceae. In: G. Martinelli \& M. A. Moraes (eds.) Livro vermelho da flora do Brasil. CNCFlora, Rio de Janeiro, pp. 1010-1016.

Salimena, F. R. G., Moraes, L., Kutschenko, D. C. \& Novaes, L. 2014. Verbenaceae. In: G. Martinelli, T. Messina, \& L. Santos-Filho (eds.) Livro vermelho da flora do Brasil - Plantas raras do Cerrado. CNCFlora, Rio de Janeiro. pp. 266-273.

Sanders, R.W. 2001. The genera of Verbenaceae in the southeastern United States. Harvard Papers in Botany 5: 303-358.

SEMAD. 2004. Secretaria de Estado de Meio Ambiente e Desenvolvimento Sustentável. Plano de Manejo do Parque Estadual do Pico do Itambé. SDS-01/02, Curitiba.

Silva, T.R.S. 1999. Redelimitação e revisão taxonômica do gênero Lantana L. (Verbenaceae) no Brasil. Tese de Doutorado, Universidade de São Paulo, São Paulo.

Thiers, B. 2020. Index Herbariorum: A global directory of public herbaria and associated staff.New York Botanical Garden's Virtual Herbarium. Disponível em http:// sweetgum.nybg.org/ih/ (acesso em 16-I-2020).

Versieux, L. M. 2008. Checklist and one new species of Bromeliaceae from Pico do Itambé, Minas Gerais, Brazil. Botanical Journal of the Linnean Society 158 : 709-715. 